\title{
Social Politics and Criminal Politics of Covid-19 Response: Case in Indonesia
}

\author{
Safik Faozi ${ }^{1}$--- Bambang Sudiyatno ${ }^{2 *}$--- Widiyanto Tri Handoko ${ }^{3}$ \\ ${ }^{1,2, s}$ University of Stikubank (UNISBANK), Semarang, Indonesia. \\ Email:safikfaozi@edu.unisbank.ac.id \\ ¿Email:bsud@edu.unisbank.ac.id \\ smail:wthandoko@edu.unisbank.ac.id
}

\begin{abstract}
The handling of COVID-19 is a social policy to protect the public from the spread of COVID-19 which has endangered the safety of life and the survival of the community, nation, and state. This social policy can be carried out through rational and total efforts to tackle the spread of COVID-19. Enforcement of the rule of law by imposing sanctions for violators is an implementation of criminal political efforts. The integration of the response is carried out by rationally integrating penal and penal approaches that are based on social protection, such as the use of media to build public awareness, involvement of networks of strategic figures, science-based control management, use of information technology to prevent the spread of COVID-19 and the provision of direct assistance. integrated cash, as well as the application of criminal sanctions that function as a subsidiary.
\end{abstract}

Keywords: Social policy, Social-politics, Criminal politics, Social-protection, COVID-19.

JEL Classification: I12, I18, K30, K32.

Licensed: This work is licensed under a Creative Commons Attribution 4.o License.

Funding: This study received no specific financial support.

Competing Interests: The authors declare that they have no competing interests.

\section{Background to the Study}

The existence of infectious diseases caused by viruses has existed since hundreds of years ago, and its existence is increasingly complex along with global travel. According to Lim (2014) and Lindahl and Grace (2015) that the level of complexity surrounding emerging and re-emerging infectious diseases has increased with the ease and increasing incidence of global travel, along with greater global social, economic, and political integration. Meanwhile, according to Kilbourne (2006) with reference to pandemic influenza, but still applies to many infectious diseases and vector-borne diseases, the only certainty is the increasing uncertainty of the emergence of infectious diseases with pandemic potential, their origins, characteristics, and biological pathways. through which they spread (Bickley, Chan, Skali, Stadelmann, \& Torgler, 2021).

In the last 2 decades, the world has been re-busy with the Covid-19 outbreak which continues to this day. As stated by Callaway, Cyranoski, Mallapaty, Stoye, and Tollefson (2020) that the coronavirus disease (COVID-19) is fueling a global pandemic and economic contraction unlike anything seen for about a century. COVID-19 is less deadly than many other new diseases, such as Ebola, Avian Flu, and Tuberculosis.

This epidemic has not only caused losses in the health, economic, social fields, but has touched the community in the fields of education, culture, worship and even threats in the fields of defense and state security. So worried about the development of the spread of COVID-19, the government issued a policy that limits work activities and community activities with the term Large-Scale Social Restrictions (PSBB). 
Furthermore, when the Covid-19 condition increased, then raised it to an emergency condition with a new term, namely the Implementation of Emergency Community Activity Restrictions (PPKM). Even the results of the evaluation of the Implementation of Community Activity Restrictions (PPKM) when this article was written were given levels based on the situation and conditions that took place in each community, namely PPKM level 3 and level 4.

The response to the spread of COVID-19 is complex because it touches all the basic joints of society, namely public health needs and the fulfillment of community food needs, as well as social, economic, cultural, educational, ideological and public defense in the security sector. The urgency of handling COVID-19 has entered the emergency category. For this reason, the prevention approach that has been seen so far in the aspect of economic activity is considered not to solve the problem but instead is increasingly endangering people's lives, considering the spread rate that touches confirmed positive patients is above 55,000 every day (when this article was written) and has threatened the availability of oxygen that had been experiencing scarcity in several large hospitals including Dr. Sardjito Yogyakarta.

The complexity of handling the spread of COVID-19 is increasingly difficult to deal with with the level of community discipline in complying with health protocols. This condition is an obstacle in the enforcement of strict health protocols in the community, moreover community disobedience is often a cultural fact of the Indonesian people (Koentjoroningrat's study which describes the cultural disobedience of the Indonesian people) is also related to the fulfillment of food needs which is a basic need for people who experience limitations at the time of promulgation (Hoefnagles, 1969).

The impact of the COVID-19 outbreak has caused crises in various sectors of life, including the political, social, cultural and economic sectors. Crisis forces leaders to make high-risk decisions under conditions of threat, uncertainty, and time pressure. Crises are important because of their humanitarian consequences and political repercussions. They also tend to increase in frequency with economic globalization and climate change (Lipscy, 2020). Efforts to deal with the crisis are carried out by enforcing the rules for implementing sanctions in the context of preventing the spread of COVID-19, both imprisonment, fines, and administrative sanctions. In fact, it is not uncommon for social sanctions to be imposed.

Coping with COVID-19 by imposing criminal sanctions is the implementation of a criminal law policy (law criminal application). However, the application of criminal sanctions on the grounds of causing a deterrent effect for lawbreakers is part of criminal politics, namely a total and rational community effort to tackle crime (read: lawbreakers). In criminal politics, the effort to apply criminal law (criminal law application) turns out to have limitations in criminal law, especially because it involves intersecting social issues, namely public health and community food needs. People's desperation to continue working to meet food needs is a socio-economic problem that cannot be overcome by threatening or punishing violators.

Although various efforts have been made to provide understanding to the public regarding the dangers of COVID-19, there are still many people who dare to violate and even tend to dare to fight against officers. This phenomenon occurs almost every day that we can see through social media, both television, YouTube, and other social media. This means that other methods are needed that can be used to complement the limitations of the approach to imposing sanctions for perpetrators that have been carried out so far, namely a criminal political approach to prevent the spread of COVID-19.

\section{Research Question}

i. What is the approach to criminal politics in the perspective of social politics in dealing with the spread of COVID-19?

ii. What is the approach to criminal politics in the perspectives on the implementation of sanctions for handling COVID-19?

\section{Literature Review}

Social policy is a plan or action of government or institutional agencies which aim to improve or reform society. It consists of guidelines, principles, legislation and associated activities that affect the living conditions conducive to human welfare, such as a person's quality of life. The Malcolm Wiener Center for Social Policy at Harvard University describes social policy as "public policy and practice in the areas of health care, human services, criminal justice, inequality, education, and labor" (The Malcolm Wiener Center for Social Policy, 2015). Social policy might also be described as actions that affect the well-being of members of a society through shaping the distribution of and access to goods and resources in that society (Cheyne, O'Brien, \& Belgrave, 2005). Social policy often deals with wicked problems. The existence of a crime problem that is troubling the community must be prevented and overcome. Prevent deviant behavior or crime is criminal policy. This is a part of social policy.

In its widest sense, criminal policy refers to all actions that influence criminality. Criminal policy includes, for example, decision-making concerning which acts constitute punishable offences, what kind of punishments are imposed for these offences, and how severe these punishments are. In addition to criminal law measures, alcohol policy measures, social and education policy measures, health care service arrangements and urban planning, among other things, affect criminality. 
The goal of criminal policy is to realize the welfare of the community, namely by providing guarantees for the welfare of the community, education and employment of the population. These conditions are the basis for a safe community life. The objective of criminal policy is to reduce criminality and its harmful effects. Crime prevention efforts are the primary means for achieving this. Another objective is to increase safety and sense of security in society. G. Peter Hoefnagels formulates criminal political efforts through influencing society of crime and punishment, law criminal application and prevention without punishment. Specifically, crime prevention without punishment is carried out through social policy, community planning mental health, national mental health, social work child welfare, administrative \& civil law.

To enforce laws and regulations, the government can use a social policy approach, namely using community leaders to socialize the applicable laws and regulations so that these laws and regulations are more effectively accepted by the community. The stipulation of laws and regulations in controlling COVID-19 still faces many obstacles, for example in the protocol for burial of bodies exposed to COVID-19 in several places, there are still many rejections from the community. To prevent a similar situation from occurring, the government needs to involve community leaders in the area to provide an understanding so that the community obeys the regulations.

Taking power during the COVID-19 pandemic poses many complex issues that need to be resolved. The solution to this problem requires a stable and resilient framework to shape and guide decision making (Jarman, 2021). Related to this problem, it is necessary to involve community leaders so that the decisions taken reflect the decisions that are really needed by the community, and the community does not feel disadvantaged by the decision. For example, the decision to handle the COVID-19 pandemic. Thus, social policy carried out as an action to deal with COVID-19 will become more effective.

On the other hand, the handling of COVID-19 is carried out using a criminal political approach. Criminal politics is a rational effort to tackle crime. Criminal politics as a science as well as a means of tackling criminal acts is deemed capable of cracking down and overcoming this phenomenon, both through penal and non-penal means.

Criminal Politics as a rational effort of society in tackling crime operationally can be carried out either through penal or non-penal means. Enforcement of criminal law in dealing with COVID-19 criminal acts cannot only use penal facilities but also use non-penal means. When viewed from the perspective of criminal politics at a macro level, the policy of overcoming the COVID-19 crime by using means other than criminal law is the right policy. This is because non-penal efforts are more of a preventive measure against the occurrence of COVID-19 criminal acts. The main target of non-penal policies is to deal with and eliminate the conducive factors that cause the occurrence of these crimes.

This study aims to examine the policies of the Indonesian government in dealing with the spread of COVID-19 which is carried out with a criminal political approach from a socio-political perspective.

\section{Methods}

This research is an observational study using primary data taken by conducting direct observations and interviews with people affected by COVID-19. Information data collection is also carried out through the media, both print media, television, YouTube, Facebook, and other electronic media

\section{Discussion}

Domestic policies implemented in response to the coronavirus pandemic range from school closures and the cancellation of public events to full-scale national lockdowns. Previous research has suggested that democratic countries, especially those with competitive elections, are quicker to close schools (Bickley et al., 2021). Interestingly, those with high government effectiveness (i.e., those with high quality public and civil services, policy formulation, and policy implementation) were slower to implement the policy (Cronert, 2020) as were more right-leaning governments (Adolph, Amano, Bang-Jensen, Fullman, \& Wilkerson, 2020).

The policy adopted by the Indonesian government uses a criminal policy approach. From this approach, the analysis is carried out using a criminal policy approach in a socio-policy perspective and the implementation of sanctions for handling COVID-19?

\subsection{Criminal Politics in the Perspective of Social Policy Handling the Spread of COVID-19}

Criminal politics as stated by Sudarto is a rational effort of society to tackle crime. Marc Ancel defines criminal politics as the rational organization of the social reactions to crime (Hoefnagles, 1969). Hoefnagles (1969) which gives the meaning of criminal policy in various senses, such as the expression that the science of criminal policy is the science of crime prevention, criminal policy as a science of policy is part of a larger policy: the law enforcement policy. Nawawi (1996) illustrates the approach to criminal politics as part of social politics as presented in the Figure 1 below: 


\section{SKEMA CRIMINAL POLICY G. PETER HOEFNAGELS}

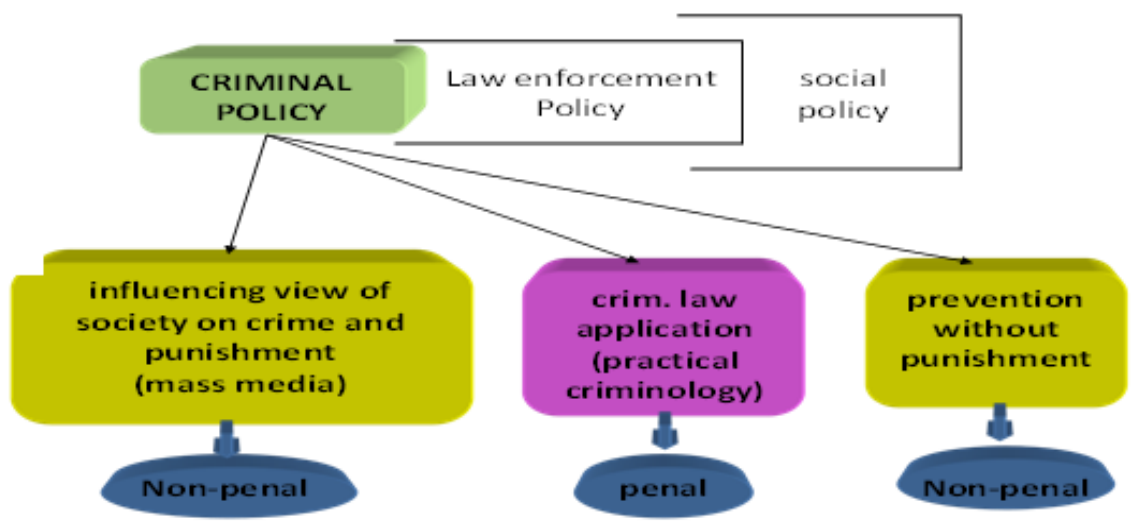

Source: Hoefnagles (1969).

Figure-1. Skema criminal policy.

Overcoming violations of the legal provisions of large-scale social restrictions are intended to create a safe, peaceful life. The need to realize a safe and peaceful community life is a means to realize a just and prosperous community life which is illustrated by the "tata tentrem and kerta rahardja". A safe, just and prosperous community life is a social policy that must be realized by the state as mandated in the fourth paragraph of the 1945 Constitution, namely protecting the community, educating and realizing public welfare.

The social politics mandated by the 1945 Constitution to state administrators as carried out by the Government is related to the protection of the community against the spread of COVID-19, namely the sacred mandate of the 1945 Constitution to protect the community against the spread of COVID-19 and to ensure that the community still has its basic needs fulfilled to avoid the life of the people who are suffering from poverty not prosperous. To realize social policy against the spread of COVID-19, apart from having to be based on rationality - as a characteristic of the policy approach - one must also open to alternative choices of policies taken.

An open and rational approach to social policy in dealing with the spread of COVID-19 indicates an approach that is not emotional in nature, but rather an approach that is built based on knowledge that is full of rational values. Law Number 6 of 2018 concerning Health Quarantine as a state policy has determined the existence of a regional, home, hospital or social quarantine policy for the prevention and control of an epidemic that is contagious.

Under Chapter 49 states that the policy must be based on epidemiological considerations, the magnitude of the threat, effectiveness, resource support, operational technical, economic, social, cultural and security considerations. The existence of a state policy in the form of large-scale social restrictions indicates that the state policy has been built based on rational considerations. Although social policies have been based on rational considerations, the problem is that the choice made by the government is large-scale social restrictions, not the option of regional quarantine or home quarantine as also alternatively by Law Number 6 of 2018 concerning Health Quarantine.

The choice to quarantine the territory voiced by the community has been defeated by economic and business interests. Even in 2020 the Governor of Jakarta who took the policy to close the DKI area (lockdown, or according to Law No. 6 of 2018 with the term regional quarantine) was not supported by the central government and was also rejected by the owner of the Jarum Group by sending a letter of rejection in person open to the President of the Republic of Indonesia.

The dominance of economic considerations over health considerations was firmly rejected by Dr. Faisal Basri is a lecturer at the University of Indonesia and a senior INDEF economist. The government's choice of a policy of restricting community activities instead of a regional quarantine is a social policy choice to deal with COVID-19, which is still a concern for the community, even though this policy has been going on for more than 16 months.

The social-political approach that is full of rational choices built based on of science teaches that the powerlessness of a falsified method requires replacing it with another method. Social restrictions coupled with vaccinations that are not recommended by the World Health Organization (WHO) are not sufficient to reduce the spread of COVID-19. For this reason, it is necessary as a social policy to provide alternative vaccine options recommended by the World Health Organization (WHO).

On the other hand, other methods are also needed outside of large-scale social restrictions (PSBB) or the imposition of restrictions on community activities (PPKM). Another alternative social policy determined by the law is the Regional Quarantine as stipulated in Chapter 53 paragraph (1) which emphasizes that the regional quarantine is part of the response to a public health emergency. This responsibility of the Central 
Government may also involve the Regional Government and other related parties (Chapter 55). This means that there is a shared responsibility for efforts to overcome COVID-19 under the control of the Central Government.

The policy to carry out a regional quarantine or a lockdown that limits the entry and exit of the region was also mentioned again during the regional restriction policy at the level by Jusuf Kalla, the former Vice President, as well as by Dr. Rizal Ramli, namely the implementation of the closure of the area and the provision of basic needs of the community. The proposal submitted by Jusuf Kalla requires $60 \mathrm{~T}$ per month for 6 months (The rough calculation is that there are 60 million families with $30 \%$ receiving direct cash assistance of IDR 1,000,000/each KK every month for 6 months). Meanwhile, Rizal Ramli estimates that there will be a budget allocation of $415 \mathrm{~T}$ (A rough calculation of the provision of BLT for 70 million poor people with a nominal value of $105 \mathrm{~T}$ per month and the need for $100 \mathrm{~T}$ for 3 months) also proposed by Dr. Rizal Ramli. This effort can still be carried out by the Government, but it seems that the government prefers the Enforcement of Restrictions on Community Activities. This means that the government is still confident in its policy choices even though it has been judged unsuccessful several times in tackling the spread of COVID-19.

From the point of view of victimology, which is oriented towards minimizing the number of victims who continue to fall, the involvement with local governments and other related parties as mandated by chapter 55 teaches the basis for arguments for social contracts and social solidarity. The responsibility of the central government in dealing with COVID-19 is the implementation of the social contract argument, and involvement with other related parties is the elaboration of the social solidarity argument. The existence of Jogo Tonggo who grows voluntarily has eased the burden on the community, whether individuals, community organizations or the mosque/church movement concerned with COVID-19 in various forms such as the provision of masks, food, or personal protective equipment (PPE). The spirit of cooperation of the community to jointly share relieves the burden on the community which characterizes the community can be used as social capital to be transformed into a community movement.

\subsection{Criminal Policy Perspectives on the Implementation of Sanctions for Handling COVID-19 5.2.1. Application of Criminal Sanctions}

One of the efforts to overcome COVID-19 is the enforcement of the rules for Restricting the Enforcement of Community Activities. The enforcement of the rule of law is not in a vacuum, but in the conditions and situations of the Indonesian people who experience a disciplinary deficit against the rule of law. Myrdal (1970) once assessed that there was disobedience to the law that had become widespread and became public indiscipline. Koentjoroningrat (2015) also considers Indonesian society as an undisciplined society, likes to trespass. Given this factual condition, the government tries to enforce the rules for the PSBB or emergency PPKM by imposing strict sanctions. Law Number 6 of 2018 and Law Number 4 of 1984 and the Criminal Code have determined that there are criminal sanctions in prison, imprisonment, and a certain number of fines. Criminal threats can also be imposed through the Criminal Code starting with Chapter 212-216, and Chapter 218 of the Criminal Code. The threat is a maximum imprisonment of one year and four months or a maximum fine of Rp. 4,500, or a maximum imprisonment of four months and two weeks or a maximum fine of Rp. 9,000 (Chapter 216), or a maximum imprisonment of four months and two weeks or a maximum fine of IDR 9,000 (Chapter 218).

The threats of criminal sanctions if applied mean the application of criminal law as one of the criminal political efforts through criminal law (penal). In the study of criminal politics, the application of criminal law must consider the nature of the subsidiary functions of criminal law, on the one hand, also based on human values. This means that the application of criminal sanctions must be carried out selectively, especially when the application of criminal sanctions is faced with social conditions that force people to fulfill their basic needs.

Especially for the small business sector, for community members to meet their basic needs, such as the implementation of legal sanctions, they are still within the limits of business opening hours, online services or are dine-out. Violations of this rule of law are subject to criminal sanctions of imprisonment or fines that are still within the limits of community discipline enforcement, for example being processed in a fast court and subject to imprisonment for 1-3 days or a minimum fine. Even the enforcement of social sanctions needs to be initiated in accordance with the prevailing customs in society.

\subsection{Media Role}

Criminal policy, this effort can be done through changing people's perceptions about the dangers of behavior not complying with the legal provisions for the Implementation of Restrictions on Community Activities (PPKM). Efforts have been made through making news about the spread of COVID-19 that can make people aware of being obedient and obedient to the provisions of the law. Through print media, television and other social media, people have shown awareness to strictly adhere to health protocols, namely wearing masks, washing hands, and avoiding crowds, and limit mobility.

People's behavior has shown this change. The community has been limiting crowds to gatherings for more than a year. Meetings of residents at the RT or other region or community level have shifted to meetings through WhatsApp groups or through other social media. Even the crowd of recitations is also very limited and replaced by online recitations via youtube. Even in places of worship, there has also been a decline in worshippers either in mosques, churches, or other places of worship. Recitation awareness through 
YouTube has become a model for online recitation today. A new life behavior in several gatherings to avoid crowds has formed.

\subsubsection{Involvement of Community Leaders}

Indonesian society which is communal and obedient to the demands of role models becomes extraordinary social capital. Social capital that builds social communities that are full of demands from community leaders has become a very strategic and effective medium in social movements aware of the dangers of COVID-19. The chairman of PBNU, Kyai Aqiel Siradj, realized that the use of this media had not been maximized. He admitted that as the Chairman of PBNU with a very strong and culturally rich social capital network, from the beginning he was not involved much in building social movements. In fact, with the number of tens of millions of worshipers and their network which is full of cultural values, NU congregations and other cultural organizations are the main pillars in the movement of people who care about COVID-19. Not only can they be involved in social movements to prevent the spread of COVID-19, but also become the center of the people's movement to share and care for the victims of COVID-19.

\subsubsection{Science-Based Covid19 Control Management}

The management and institutional approach to controlling COVID-19 is considered not optimal in preventing the spread of COVID-19 based on a scientific basis. The scientific footing determined by the mandate of Law Number 6 of 2018 is the closure of the area or regional quarantine by providing a budget to meet the basic needs of the community during the regional quarantine. The existence of a large-scale social restriction approach or the Enforcement of Restrictions on Community Activities that provide the possibility for social movements to open up the potential and vulnerability to the spread of COVID-19. Moreover, this concession is dominated by pragmatic economic interests.

The experience of implementing PSBB and PPKM accompanied by vaccination programs that have not met the target has not been able to reduce the spread of COVID-19. Although vaccination has been carried out simultaneously with the implementation of PPKM, the spread of COVID-19 shows an alarming trend of increasing and creates an emergency. Policy-wise, the choice of methods that are not effective for controlling the spread of COVID-19 is reviewed to be replaced by other methods based on science and technology. The regional quarantine policy approach and guaranteeing the adequacy of basic needs on the one hand, as well as the massive acceleration of vaccinations that are effective in preventing the spread of COVID-19 and the use of community social capital networks to ease the burden on the community on the other hand. Ulil Absar Abdala's criticism regarding the management of Emergency PPKM control in the Java and Bali regions has been controlled despite the fact that the field is very serious, and the paid vaccine plan is far from a mass psychology approach when the COVID-19 pandemic is worrying the public, showing a less robust approach based on consistency of knowledge.

\subsubsection{Utilization of Information Technology}

Information technology has greatly assisted efforts to build public awareness and has even massively helped facilitate community activities in the economic, health, education, socio-cultural sectors during the massive spread of COVID-19. Several online facilities carried out by Grab, GoJeg, Bukalapak, Tokopedia, and online banking have been digitized, including health services, education, and other sectors.

Digitization has permeated all areas of life. This is also an effort to prevent the spread of COVID-19 through the use of information technology. Likewise, the use of digital mass media has also been able to influence public perceptions of the dangers of the spread of COVID-19, including public participation in supervising government policies in controlling COVID-19. Public criticism through social media has had an impact on the repeal of government policies that plan to sell vaccines in the name of the mutual cooperation vaccine program. Social media has played a major role in controlling the spread of COVID-19.

\section{Conclusion}

Based on the results of the analysis and by looking at the facts from observations that occurred during the implementation of the criminal political approach to prevent the spread of COVID-19 in Indonesia, there is still a gap between expectations and facts from the criminal political approach. Therefore, another more persuasive approach is needed by involving community leaders to prevent the spread of COVID-19. The influential community figures in question are religious leaders, traditional leaders and other figures who have great influence as people who are respected among the community.

Criminal politics against law enforcement during the COVID-19 outbreak must be part of social policy, namely community protection, both in protecting public health and preventing community poverty due to the implementation of government policies through PSBB or emergency PPKM. The social policy is to prevent the spread of COVID-19 through regional quarantine by meeting the basic needs of the community as stipulated in Law Number 6 of 2018 concerning Health Quarantine. The imposition of criminal sanctions for violators of the PSBB or emergency PPKM policies in criminal politics must be carried out by integrating the application of penal sanctions with non-penal community efforts, namely the massive use of mass media to influence public perception, involvement of social institutions. figures with culturally strategic social capital 
networks, and management of controlling the spread of COVID-19 that is consistent with relying on health sciences that are integrated with social sciences and technology.

\section{References}

Adolph, C., Amano, K., Bang-Jensen, B., Fullman, N., \& Wilkerson, J. (2020). Pandemic politics: Timing state-level social distancing responses to COVID-19. Journal of Health Politics, Policy and Law, 46(2), 211-233. Available at: https://doi.org/10.1215/03616878-8802162.

Bickley, S. J., Chan, H. F., Skali, A., Stadelmann, D., \& Torgler, B. (2021). How does globalization affect COVID-19 responses? Globalization and Health, 17(1), 1-19. Available at: https://doi.org/10.1186/s12992-02 1-00677-5.

Callaway, E., Cyranoski, D., Mallapaty, S., Stoye, E., \& Tollefson, J. (2020). The coronavirus pandemic in five powerful charts. Nature, 579(7800), 482-483. Available at: https://doi.org/10.1038/d41586-020-00758-2.

Cheyne, C., O'Brien, M., \& Belgrave, M. (2005). Social policy in Aotearoa New Zealand: A critical introduction (3rd ed.). South Melbourne, Vic: Oxford University Press.

Cronert, A. (2020). Democracy, state capacity, and COVID-19 related school closures. Working Paper, Uppsala University. $\quad$ Retrieved from: https://preprints.apsanet.org/engage/apsa/articledetails/5ea8501b68bfcc00122e96ac.

Hoefnagles, G. P. (1969). The other side of criminology: An inversion of the concept of crime. Holland: Cluwer Deventer.

Jarman, R. (2021). Power, politics and policing: How the pandemic has highlighted fractures and fault lines in our society. Journal of Global Faultines, 8(1), 100-113. Available at: https://doi.org/10.13169/jglobfaul.8.1.0100.

Kilbourne, E. (2006). Influenza pandemics of the 20th century. Emerging Infectious Diseases, 12(1), 9-14. Available at: https://doi.org/10.3201/eid1201.051254.

Koentjoroningrat. (2015). Culture, mentality, and development. Jakarta: PT. Gramedia Pustaka Utama.

Lim, P. L. (2014). Travel and the globalization of emerging infections. Transactions of the Royal Society of Tropical Medicine and Hygiene, 108, 1309-1310. Available at: https://doi.org/10.1093/trstmh/tru051.

Lindahl, J. F., \& Grace, D. (2015). The consequences of human actions on risks for infectious diseases: A review. Infection Ecology \& Epidemiology, 5(1), 30048. Available at: https://doi.org/10.3402/iee.v5.30048.

Lipscy, P. Y. (2020). COVID-19 and the politics of crisis. International Organization, 74(S1), E98-E127.

Myrdal, G. (1970). The challenge of world proverty. Harmond Worth: Penguin Books.

Nawawi, A., B. (1996). Limits of criminal law capability in combating crime. Paper presented at the National Seminar Paper on Non-Penal Approaches in Crime Prevention, Semarang.

The Malcolm Wiener Center for Social Policy. (2015). Presidents and fellows of Harvard. Harvard Kennedy School. Retrieved from: https://www.hks.harvard.edu/centers/wiener/news-events/news-archive. 